\title{
Correction to: Normalization of magnesium deficiency attenuated mechanical allodynia, depressive-like behaviors, and memory deficits associated with cyclophosphamide- induced cystitis by inhibiting TNF-a/NF-KB signaling in female rats
}

\author{
Jia-Liang Chen ${ }^{1 \dagger}$, Xin Zhou ${ }^{2 \dagger}$, Bo-Long Liu ${ }^{1 \dagger}$, Xu-Hong Wei ${ }^{2}$, Hong-Lu Ding ${ }^{1}$, Zhi-Jun Lin ${ }^{1}$, Hai-Lun Zhan ${ }^{1}$, \\ Fei Yang ${ }^{1}$, Wen-Biao Li ${ }^{1}$, Jun-Cong Xie ${ }^{1}$, Min-Zhi Su ${ }^{4}$, Xian-Guo Liu ${ }^{2,3^{*}}$ and Xiang-Fu Zhou ${ }^{1 *}$
}

Correction to: J Neuroinflammation 17, 99 (2020) https://doi.org/10.1186/s12974-020-01786-5

Following publication of the original article [1], the authors noticed some mistakes in the published article as follows:

1. Methods, Drug administration:

"Briefly, CYP (25 mg/kg; Sigma, St Louis, MO) was intraperitoneally..." should be corrected as following "Briefly, CYP (50 mg/kg; Sigma, St Louis, MO) was intraperitoneally...". The dose of CYP we used in this research should be $50 \mathrm{mg} / \mathrm{kg}$ (same as described in Abstract) but not $25 \mathrm{mg} / \mathrm{kg}$.
2. The histogram in Fig. 11c is mistakenly used. It is the same as the histogram in Fig. 8c. The $\mathrm{Y}$ axis title of Fig. 11d should be corrected to "NR2B/actin (\% of Veh)". Presented here is the corrected Fig. 11.

The original article has been updated.

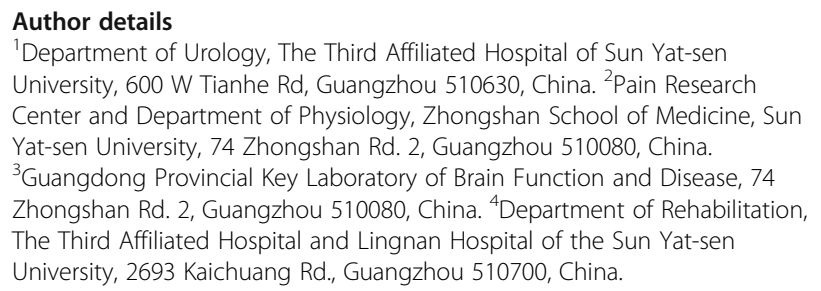

Published online: 14 November 2021

\section{Reference}

1. Fortin SP, Johnston SS, Schuemie MJ. Applied comparison of large-scale propensity score matching and cardinality matching for causal inference in observational research. BMC Med Res Methodol. 2021;21:109. https://doi. org/10.1186/s12874-021-01282-1.

\section{0-01786-5.}

* Correspondence: liuxg@mail.sysu.edu.cn; zhouxfu@mail.sysu.edu.cn

${ }^{+}$Jia-Liang Chen, Xin Zhou and Bo-Long Liu contributed equally to this work. ${ }^{2}$ Pain Research Center and Department of Physiology, Zhongshan School of Medicine, Sun Yat-sen University, 74 Zhongshan Rd. 2, Guangzhou 510080, China

'Department of Urology, The Third Affiliated Hospital of Sun Yat-sen University, 600 W Tianhe Rd, Guangzhou 510630, China

Full list of author information is available at the end of the article

(c) The Author(s). 2021 Open Access This article is licensed under a Creative Commons Attribution 4.0 International License, which permits use, sharing, adaptation, distribution and reproduction in any medium or format, as long as you give appropriate credit to the original author(s) and the source, provide a link to the Creative Commons licence, and indicate if changes were made. The images or other third party material in this article are included in the article's Creative Commons licence, unless indicated otherwise in a credit line to the material. If material is not included in the article's Creative Commons licence and your intended use is not permitted by statutory regulation or exceeds the permitted use, you will need to obtain permission directly from the copyright holder. To view a copy of this licence, visit http://creativecommons.org/licenses/by/4.0/. The Creative Commons Public Domain Dedication waiver (http://creativecommons.org/publicdomain/zero/1.0/) applies to the data made available in this article, unless otherwise stated in a credit line to the data. 

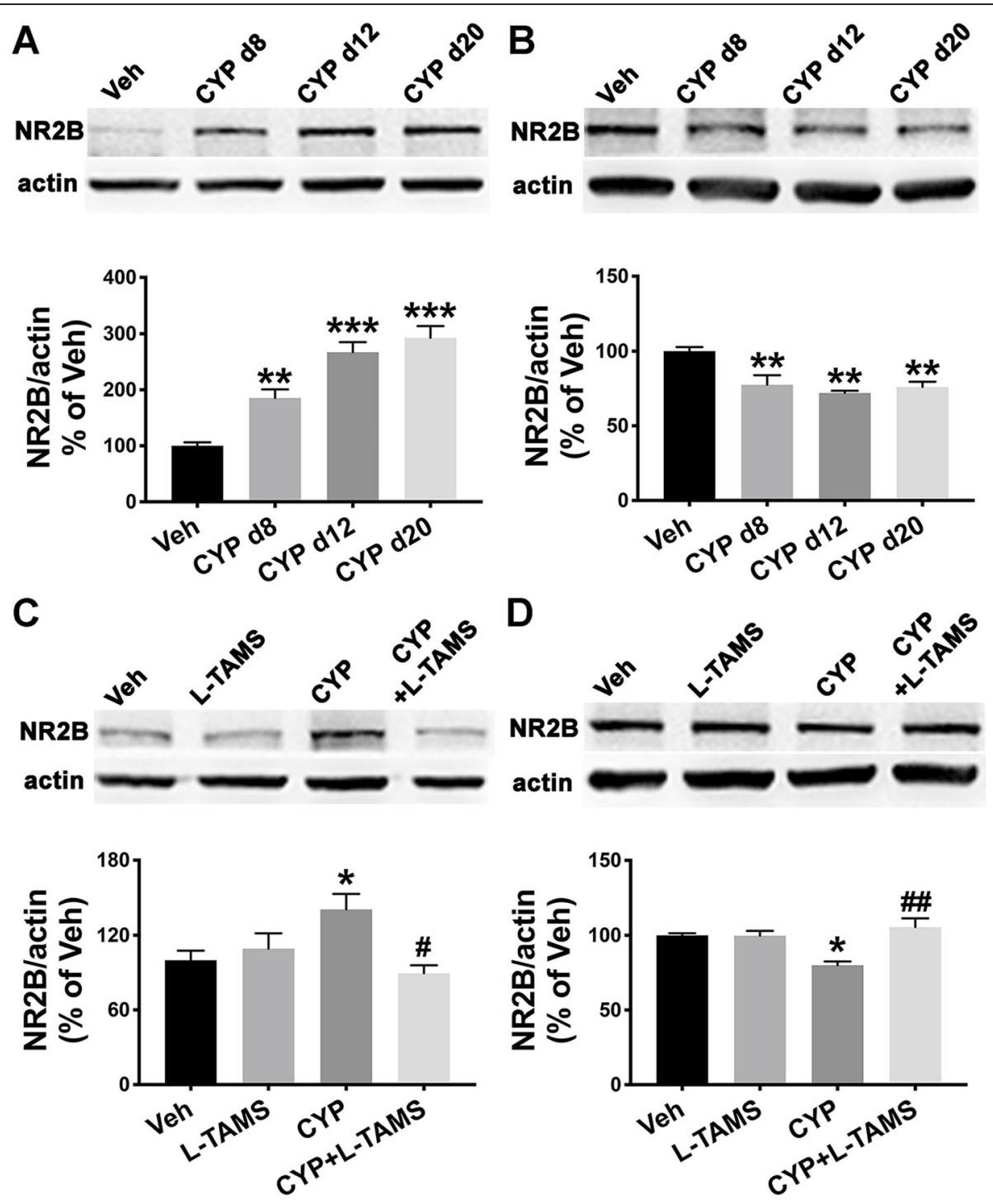

Fig. $11 \mathrm{Up}$ - and downregulation of NR2B in the SDH and hippocampus, respectively, were normalized by L-TAMS. Western blot analysis showed that NR2B was upregulated in the SDH (a) but downregulated in the hippocampus (b) of cystitis model rats at the three time points (days 8, 12, and 20 after the first CYP injection). The abnormal expression of NR2B in the SDH (c) or hippocampus (d) was neutralized by oral application of L-TAMS on day 20. ${ }^{*} P<0.05$, ${ }^{* *} P<0.01$, and ${ }^{* * *} P<0.001$ vs. Veh group, ${ }^{\#} P<0.05$ and ${ }^{\# \#} P<0.01$ vs. CYP group. Data were analyzed by one-way ANOVA followed by Tukey's post hoc test 